\title{
RELATIONSHIP BETWEEN ORIGAMI AND INTERIOR DESIGN RELATED SPACES MANIPULATION
}

Mahmoud Ahmed Hassan El Kouriny a, *

a Department of Interior Design \& Furniture, College of Applied Arts, Helwan University

\begin{abstract}
In an increasingly technological, informed and demanding society Architecture should be able to answer to its space requirements using materials and technological resources that today has at its service. The main concern of the architectural part is the form finding process which is inspired by Origami, the Japanese art of paper folding. Based on a simple technique, Origami gives birth to an astonishing formal richness and variability. Complex geometries are generated in an economic way to produce the masterpiece in the house and impress the environment.

The research aims to develop thought interior designer about origami and new ideas for the efficient usage of the new shape. To give the idea of the variable kinds, types of origami and also how to invent it to the Interior design. To show that there are a space for the creativity and field of the unknown usage for the origami, as it just has been studied. This part of the work should be inspiring for the young Designers in order to reach the new goals.

This research review new methods to generate rapidly complex folded plate structures that can be built with cross-laminated timber panels. Composition and dimensions of these panels as well as the possibility to mill them by Computer Numerically Controlled machines show a great potential for surface structures. In addition, there are suggestions how to reveal the potential in the domain of folded plate structures. An interdisciplinary team investigates architectural, structural and mathematical aspects of folded plate structures built from cross- laminated timber panels. The main concern of the architectural part is the form finding process, which is inspired by Origami, the Japanese art of paper folding. Based on a simple technique, Origami gives birth to an astonishing formal richness and variability. Complex geometries are generated in an economic way and we aim the increasing of the further usage of the origami shapes in interior design.

\begin{tabular}{ll}
\hline Keywords & \\
- & intensification \\
- & contemporary architecture \\
- & History of origami \\
- & Folding Paper \\
- & geometric
\end{tabular}
\end{abstract}

Introduction

"To most, the real beauty of origami lies in its simplicity, allowing everyone to create their interpretation of the world in paper. "

VANESSA GOULD

One of the biggest trends in the design world for the past few years has definitely been the origami.The main factors for that are:

1. Origami - the ancient art of paper folding has greatly influenced artists and designers from fashion to architecture, inspiring numerous origami style products and spaces. 
2. Today's intensification of social and urban change, coupled with the responsibility of issues of sustainability, amplifies the demand for interactive architectural solutions. In the context of architectural need, the attribute of being able to adapt to changing needs is paramount in contemporary society.

3. The growing interest to origami. The origami is definitely a trend today, so we were trying to look into the trend and how it shows in different areas of design. Origami is taken to the extreme in architecture, where the scales and sizes are much larger. The shapes are found in the structures and often in the Interior and exterior design, as the technique enables multiple frame options and various spaces with-in.

Origami has definitely become a trend in contemporary architecture, as the popular 3D modeling and rapid prototyping makes it possible to mimic the elegant but complex origamifolds into the structures. 


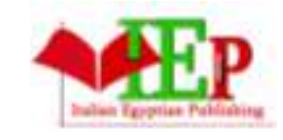

ISSN: 2785-9622
INTERNATIONAL JOURNAL OF

MULTIDISCIPLINARY STUDIES IN HERITAGE

RESEARCH

VOLUME 3, ISSUE 1, 2020, $32-50$.

www.egyptfuture.org/ojs/

\section{History of origami}

Ori (-folding) kami (-paper), is literally what its name entails. The idea is to turn a flat sheet of paper into a finished art piece by folding and sculpting, without the use of glue or scissors. Made entirely with the hands, and nothing else [2].

Japanese paper folding is thought to have originated shortly after paper was introduced to Japan via China around the 6th century AD. Rooted in the ceremonial world, most notably in the native Shinto tradition, priests performed purification rituals using zigzag strips of folded white papers known as shide. For

many centuries, members of the upper classes exchanged gifts adorned with noshi, an auspicious charm made offolded strips of paper, and gifts were typically wrapped with folded decorative paper. Paper folding as a pastime appears to have begun in the Imperial Court of the Heian period (794- 1185), and over the years became known by a variety of names, including orikata, orisue, orimono, and tatamigami. In the late 19th century, when Japan adopted the German kindergarten system, both Japanese and European paper folding techniques were incorporated into the curriculum as a way to develop children's mathematical, artistic, and manual skills, and the two folding traditions became known as origami ("folding/ed paper"). The most famous traditional origami form is the crane, which has been folded in Japan since at least theEdo period (1600-1868) and is associated with longevity.Today, the origami crane represents peace as well as long life [8].

In the mid-20th century, Akira Yoshizawa (19112005), father of modern origami, elevated Japanese paper folding from craft to art by developing new techniques, such as wetfolding, that allowed for a sculptural modeling of details. Yoshizawa also invented a system of numbersand arrows for origami folds which became the standard system of notation worldwide. A renowned teacher andauthor of numerous books on origami, Yoshizawa inspired artists internationally. Many of the artists included in

Folding Paper were influenced by Yoshizawa and by the sculptural potential of paper to create new artistic realms. In 1983 Emperor Hirohito awarded Yoshizawa the Order of the Rising Sun, a profound honor and a highlyprestigious decoration [9].
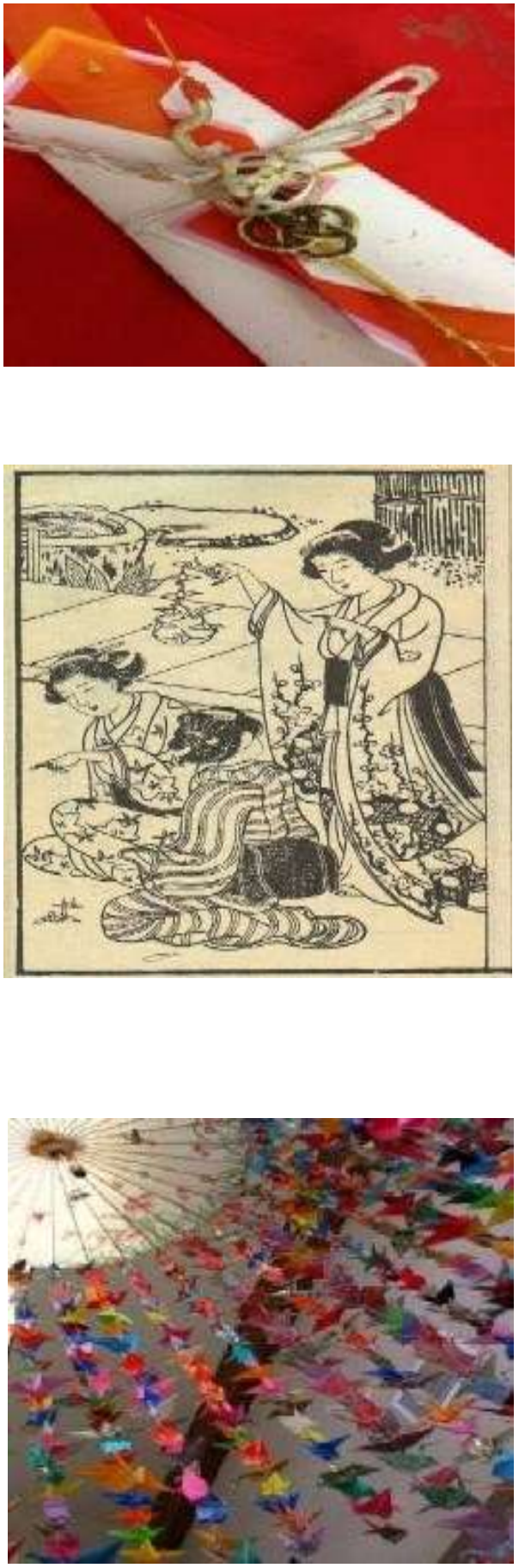

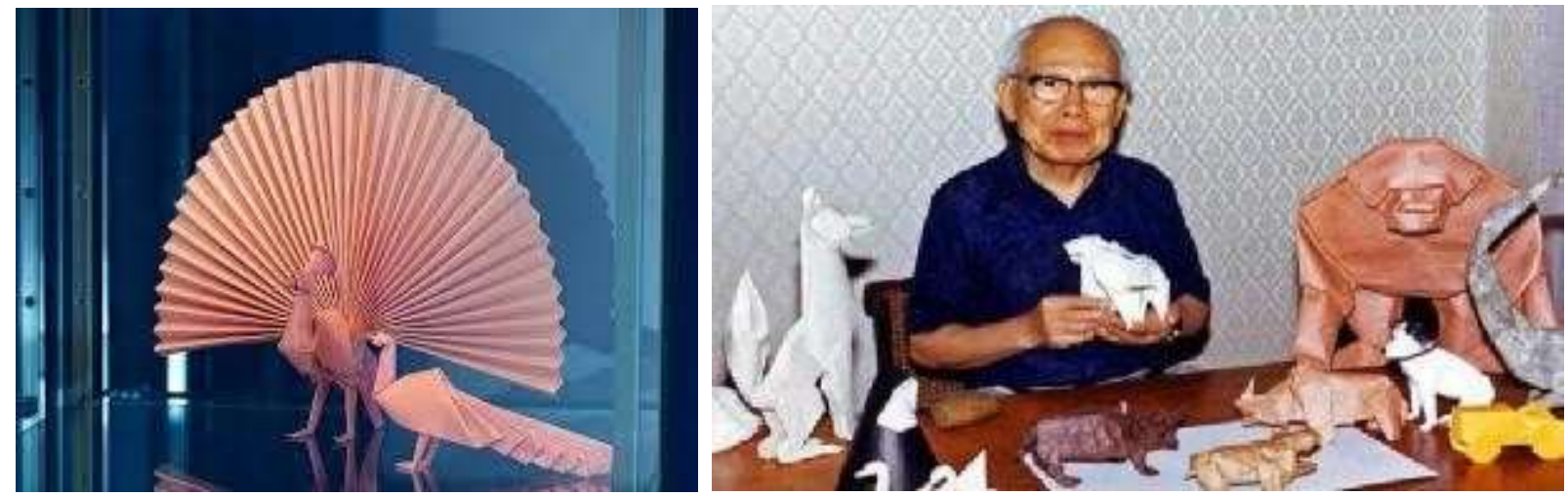

In general, we are able to separate the origami on the categories below:

- Representational Origami: one or more sheets of paper folded into an animal, flower or figure from the real or supernatural realm
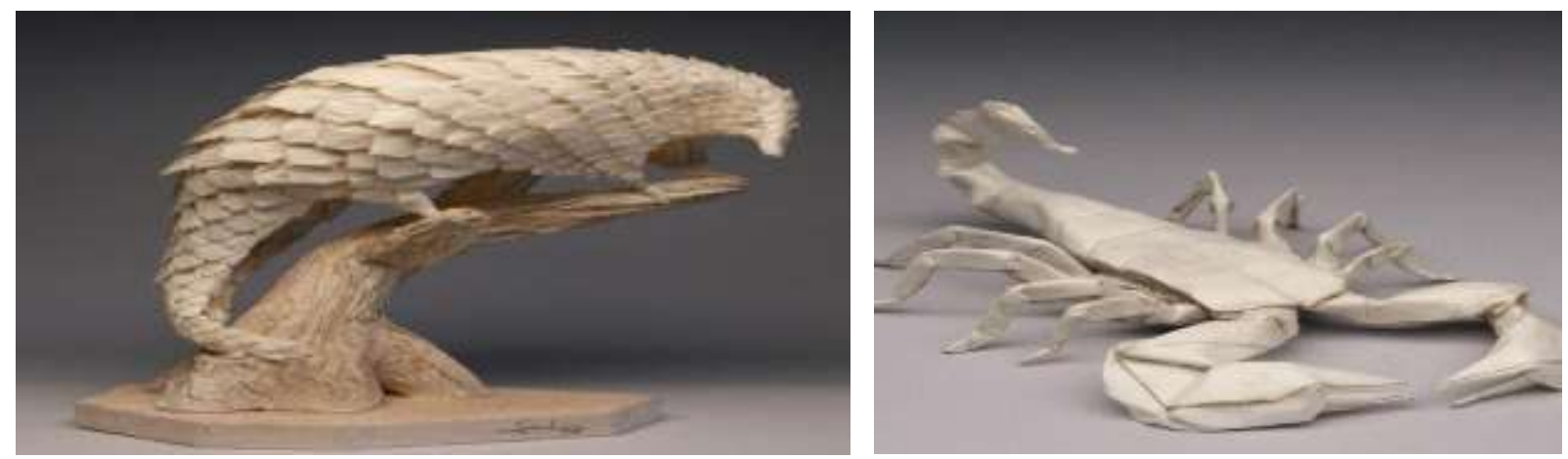

- Geometric Origami: There are two main types of geometric origami-modular origami and origami tessellations. Modular Origami: multiple sheets of paper are folded intoindividual units and then assembled into a larger, more complex geometric structure. These structures, created using mathematical calculations, are held together by friction or tension, such as that created by inserting flaps from one module into pockets of another.
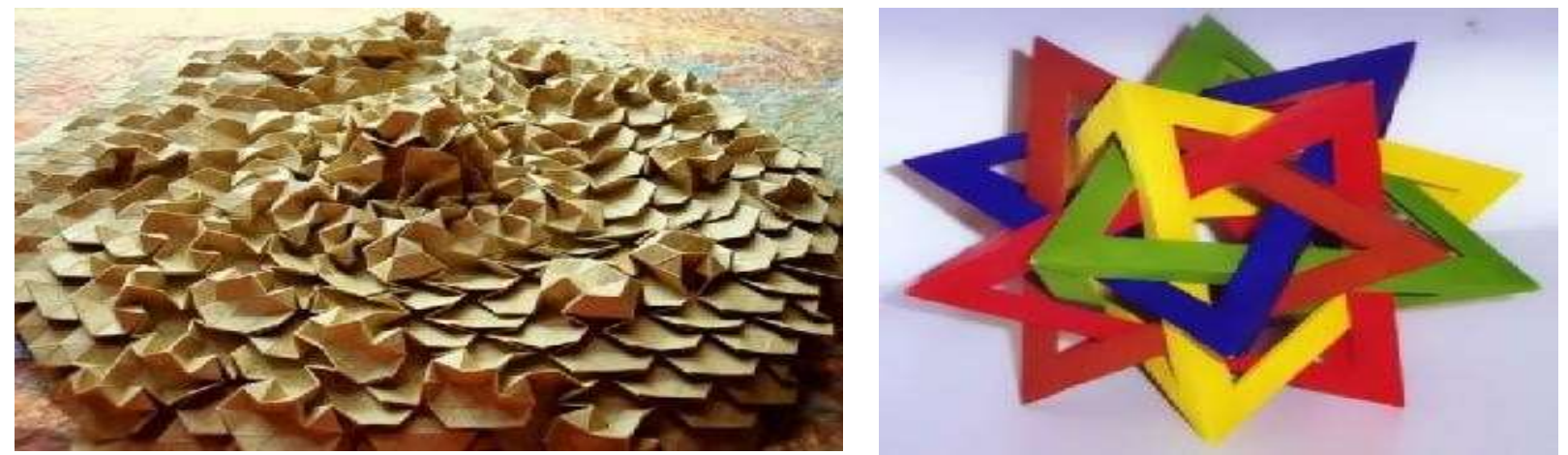


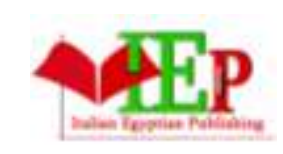

ISSN: 2785-9622
INTERNATIONAL JOURNAL OF

MULTIDISCIPLINARY STUDIES IN HERITAGE

RESEARCH

VOLUME 3, ISSUE 1, 2020, $32-50$.

www.egyptfuture.org/ojs/

- Origami Tessellation: a pattern fills a plane with no overlaps or gaps, like decorative wall tiles, often created using pleats to connect together elements such as twist folds in a repeating fashion. Many origami tessellations have the appearance of woven paper [4].
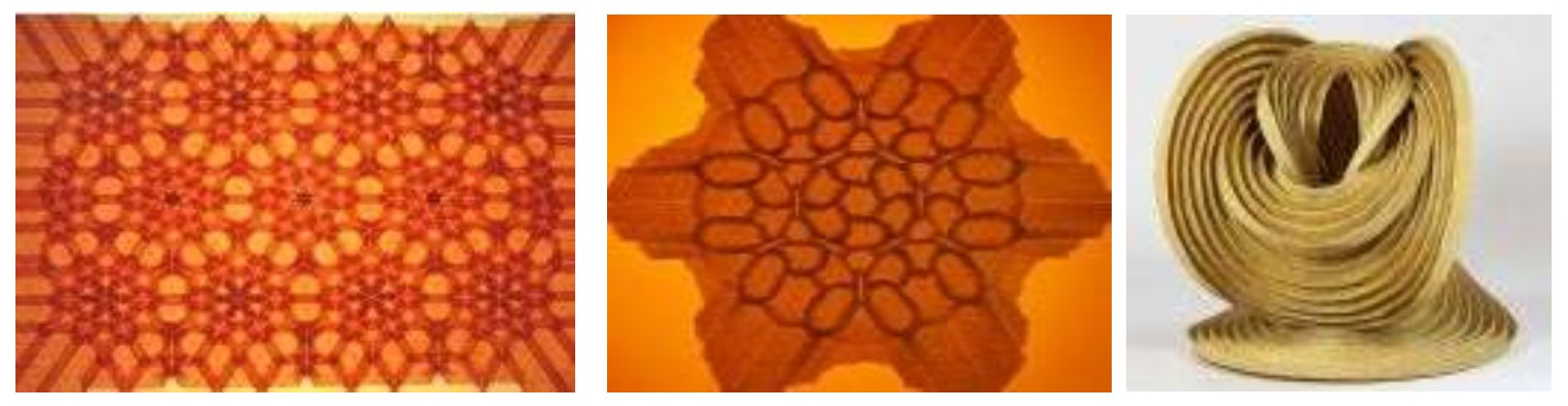

Within the context of digital fabrication advances architects are concerned both withtectonics of assembly and with synthetic surface and material effect resulting to intricate patterns through the aggregation of building materials. Foldingcan be classified [10]as one of the state of the art digital surface fabrication techniques. Certainly as a method for digital fabrication folding entails the developmentof three dimensional components into two-dimensional patterns ready for cutting by laser, water-jet or plasma cutters. While geometric development in two dimensionshas been employed in pre-digital tectonics, arts, and crafts it is today largely facilitated by software. The pre-digital unfold or crease pattern which traditionally requiredintensive geometric calculations can be easily achieved in modelling software - by theunroll or smash commands in Rhino and employing applications like Pepakura Designer. Despite the fact, the design generative potential offolding has been neglectedin computational architecture during the past few years. However, the design generative potential offolding is still needed and in demand, by embedding it within advances indigital modelling, exploiting its digital fabrication facility and enhancing its performance potential.

\section{Evolution of Origami tessellations in 20-thcentury architecture}

During the 20-thcentury many architects have explored the structural capacities, theconceptual symbolism and spatial possibilities of creating architectural forms by importingthe knowledge of Origami art into architecture. The paradigmatic projects is display on the figure 13, which provide a chronological evolution of Origami applied into architecture, focusing upon the form-generative, ornamental and structural properties of the most architecturally celebrated Origami pattern, the Yoshimura. The conceptual transformation of a two dimensional surface into a patterned, rhythmic and multiply folded plate structure comprised a recurrent theme in architectural avantgarde. The facade made by Bruno Taut at Falkenberg in 1912 represents the geometric pattern of Yoshimura. Taut used to emphasize the surfaces of facades by using prolifically contrasting brilliant color ranges. Taut was probably familiar with this design through the many publications of the beginning of the century that explored these new knowledge that connect crease patterns with mathematics, geometry and consequently with architecture. This example is used as the very first direct reference of Origami art imported,though only graphically into architecture. Drawings of Wassili Luckhardt, at the time of the "Gläserne Kette", started from a crystallographic abstraction of Switzerland Mountains [13]. In a 
few of his projects the influence of geometric exercises of representing primary figures by folding paper is evident. That kind of exercises probably inspired the ability of finding and imagining complex and innovative forms made by folding that emphasizes internal spaces in contrast to the mass of an opaque crystals and minerals. Using sequences of folds W. Luckhardt created spaces full of rhythm and vivid contrasts of light and shadows. Among the following decades 30, 40 and 50s crease geometric patterns inspire plenty of artistic works, lighting fixtures, furniture and interior designs as the circular Yoshimura dome of the dining room of the restaurant "El Coto" in Madrid, made by the architect Luís Gutiérrez Soto. In the early works by Eduardo Torroja, Pier Luigi Nerviand Felix Candela we encounter folded plate concrete shells, material efficient structurally active surfaces that are extremely thin in proportion to their load baring capacity [1].

Figure 13: Origami tessellations in contemporary architecture (top row from left)

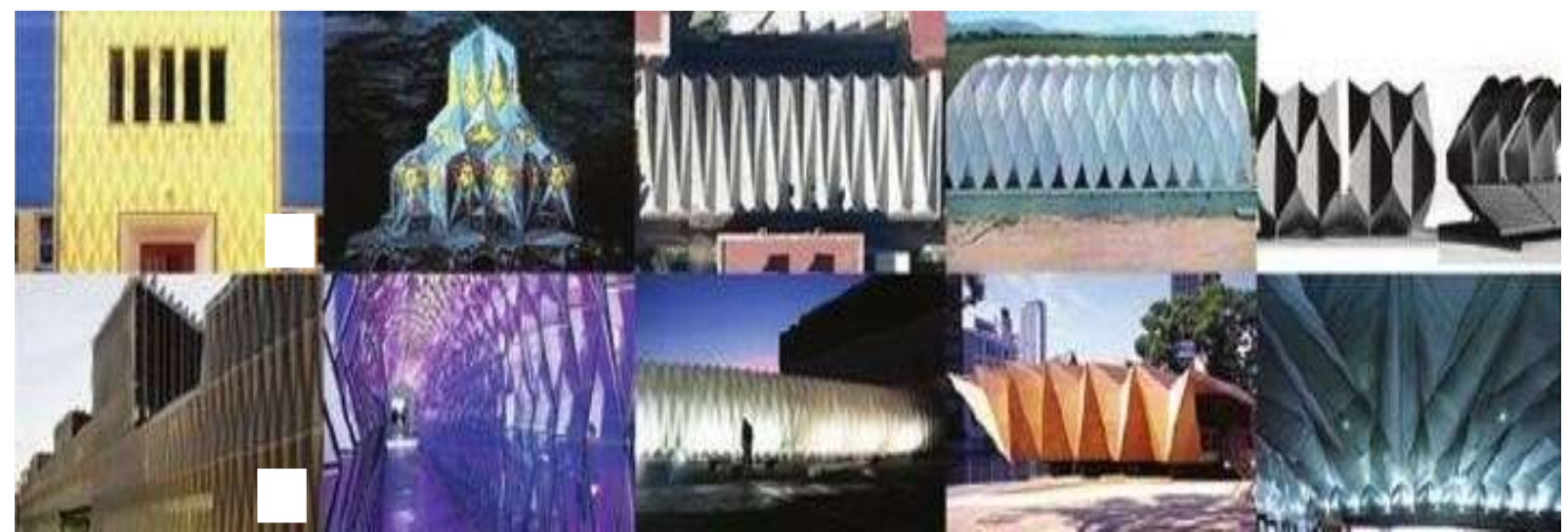

1) Facade detail by Bruno Taut,Berlin-Grunau,1912; 2) Kultusbau by Wassili Luckhardt, 1920;

3) Decks of the dining room of the Technical College of Tarragona by Eduardo Torr oja, 1956;

4) Experimental timber cover by Renzo Piano, Genova, 1965; 5) Stadium and sports complex by Jorn Utzon, Jeddah, 1967; 6) Biomedical Research Center by Va illo \& Irigaray \& Galar, Navarra, 2011; 7) One way color tunnel, by Olafur Eliasson, San Fra ncisco Museum of Modern Art, 2007; 8)Foldable Plastic Tube by Mats Karlsson for Stockholm Design Week, 2008; 9)Wooden Pavilionin Nakanoshima Park by Ryuichi Ashizawa, Osaka, 2009, 10) Passenger Terminal by Foreign Ofce Architects, Yokojama 2001 . Source: [1, 13]

Since the late 60 's folded shells also appear in timber, as well as cardboard. While the structural and plastic qualities of Origami tessellations in architectural surfaces prevail, little has been achieved with respect to kinematics. According to Fernando Cassinello not only were the complexities of calculation that halted the application of folding patterns into architectonic structures, but also the aesthetic prejudices in a new way that would break with the doctrines in vogue, giving the spectacular triumph of aggressive, dynamic and personal architecture of Frank Lloyd Wright, as a favorable factors to acceptance. To this would be added the expressiveness and movement of the forms developed from crease patterns in contrast with the clean and pure rationalist, purists, and neoclassical volumes, in which the inclined line and planes had no place in its immutable creed of parallelism and orthogonality [3]. The completion of the construction of the passenger terminal at the port of Yokohama in 2002has re-established within architectural practice the implementation of geometries derived from faceted surface elements inspired by Origami. In the past decade, folding hasfruitfully expanded its popularity among students of architecture as a resource for formal exploration. Conducting working models through folding 
and cutting paper hashelped the understanding and development of complex geometries as well as theircorresponding spatial mechanisms.

\section{Kinetic system and origami}

3.1. Kinetic system . The kinetic systems [6] can be classified inthree kinds of structures: embedded, dynamic and deployable.The embedded kinetic structures are systems within an architectonicwhole at a fixed location. Their primary function is to help control the wholein response to changing conditions. The dynamic systems act independently of the architectural whole, likedoors, movable walls, etc.The deployable kinetic systems are usually easily constructed
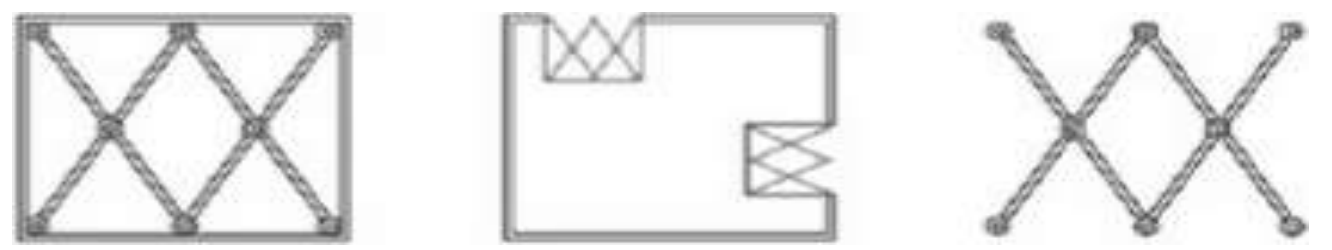

and deconstructed systems that exist in a temporary location [6].

Figure 14, 15, 16: Embedded, Dynamic, and Deployable kinds of kinetic system. Source: [6]

3.2. Geometric origami . Origami's mathematical and geometric capabilities have been studied and used by mathematicians, physicists, architects and in biology research. Despite of origami's usage for thousands of years it was only in the 80's that were defined the 7 axioms that systematize and resume origami's geometric potential, the Huzita-Hatori axioms, quite similar to the Euclidian axioms. With these axioms one can build several mathematical models with origami such has platonic solids, fractals, tessellations,

symmetries [11, 4]. The magic of these models is that much of the folding happens by itself, due to the physical properties of paper the origamist only has to crease all the folds, this way the memory of the paper is changed and,quite naturally, it chooses the position that minimizestensions. By applying specific forceswe can collapse them into a bi-dimensional form and when we let go themodels "choose" their state without the need to apply other forces or to support them in any way. The state they choose is the result of the strength donewhen creasing (or the time that the material was forced to remain in the fullyfolded position)and its geometry [5].In addition to this form of "comfort", itis possible to make also the same surfaceadapt to various geometries, volumes and areas simply by opening more orless the angles between the faces and by applying forces at strategic points. There are several kinds of origami. The one that is the most common for architecture is and rigidorigami because of its imposition that all faces remain planar at all times. Arigid origami folded surface works as multiple faces connected by folds, which function as hinges, which gives the surface an elastic capacity. A surfacelike this can grow and 
shrink despite of the used material is rigid and has no elasticity.These are the reasons that make these folded surfaces particularly suitedto meet the demands of a structure that one wants to be light, with self-supporting properties, able to assume different forms and have a kinetic behavior.

Generally, we can summarize that the use of origami in Architecturemore commonly in a frozen state, from the range of forms that a surfacemay assume it is chosen one that is reproduced in a static way with heavymaterials such as concrete, wood, metals, etc. Also we can select the phases of the research design process used to develop the Kinetic system as follow:

1. Study geometrical and mathematical properties of classical origami to generate rigid foldable structures;

2. Explore kinetic possibilities offolding transformable structures and material selection;

3. Building the prototype.

In the first phase the research started with the study of regular and irregular origami crease patterns and the existing programs and algorithms thatwould help us simulate and testtheir kinetic potential.The second phase consisted in building small scale prototypes with different materials and different mechanic systems.Finally in phase 3 we built a real scale prototype.

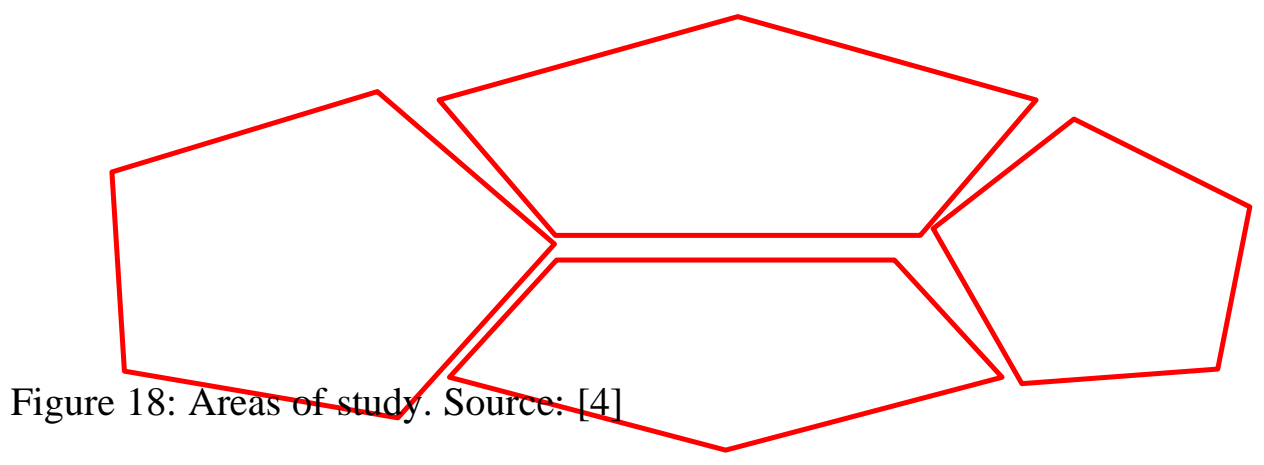

All the information that we have reviewed above was considered mostly the theoretical development of origami, its implementation and usage. In the next chapter, we will try to classify more in details the practical usage of the origami on the modern architecture.

\section{Folding patterns}

Three patterns are identified to be particularly interesting for architectural and structural applications: Yoshimura pattern, Miura Ori pattern and Diagonal pattern. The three of them are based on a combination of simple accordion folding and reverse fold: A series of straight valley andmountain folds are bent by the reverse folds to form simple curved surfaces.

4.1. Yoshimura Pattern (Diamond Pattern). The basis of this pattern is a diamond shape fold in one of its diagonals. It is named after a Japanesescientist who observed that thin walled cylinders show this kind of buckling pattern under axialcompression [7]. If in a regular diamond pattern all parallel diagonals of one direction are fold asvalley folds and the edges as mountain folds one get a cylindrical shape. 


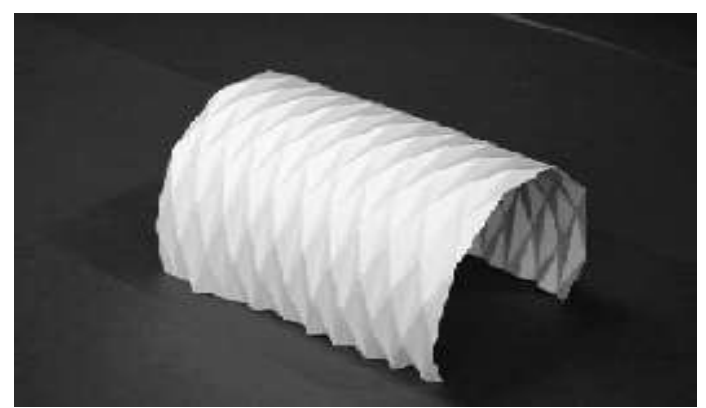

iagonal

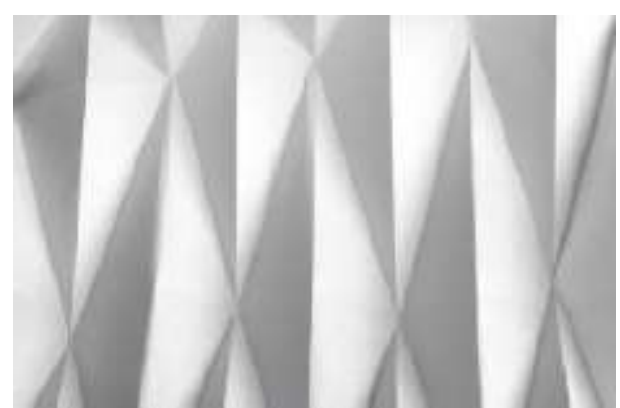

4.2. D

of this pattern is a parallelogram folded in its diagonal. Out of a parallel position the edgesare turned up diagonally. A series of so folded parallelograms form a helical distorted folding. Asimilar buckling pattern appears when a thin walled cylinder shell is compressed with a distortion[7]. Yoshimura- and diagonal- pattern are close to each other. They mainly differ by the fact thatvalley folds of diamond pattern form a plane polygonal line whereas the valley folds of the diamondpattern form a helical polygonal line.
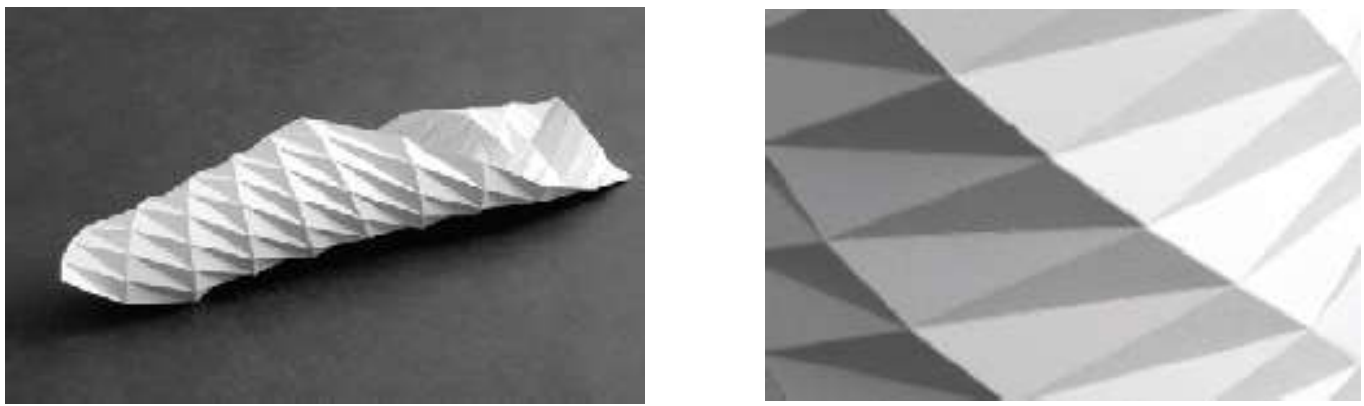

4.3. Miura Ori Pattern (Herringbone Pattern ). As the diamond pattern, this pattern can be obtained by a repetition of reverse folds. Instead ofmirroring the reverse folds they are repeated in line so that the main crease describesa zigzag line.Therefore the folded pattern has a characteristic zigzag corrugation in two directions. This allowsextending and retracting the pattern in both directions. Miura [12] used this capacity to build solarsails for satellites that could be packed in very compact way and once unfolded, have maximumextension. The pattern is composed of symmetric trapezoids that form a herringbone tessellation. The legs of the trapezoids (non parallel sides) are inclined in the same direction. In general thezigzag line of the main fold follows a curve. This is due to the difference of inclination of the legs.If the legs are parallel so that the trapezoid forms a rhomboid, the zigzag line extension of themanifold is straight. If one of the bases (parallel sides) of 
the trapezoid is reduced to zero the patternis composed of symmetrical 
triangle that form a dart. This is only possible when the legs of thetrapezoid are not parallel.
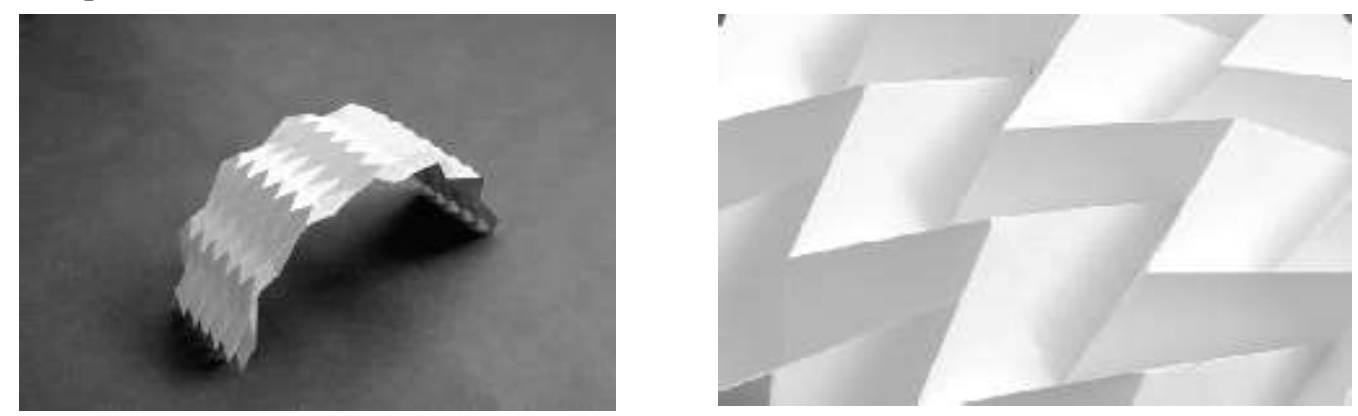

The construction of a prototype had the following goals: demonstrate the feasibility of timber panelstructures based on the proposed geometries, get some first experience with connections andassembling methods and compare the deformation of the prototype with a numerical model.
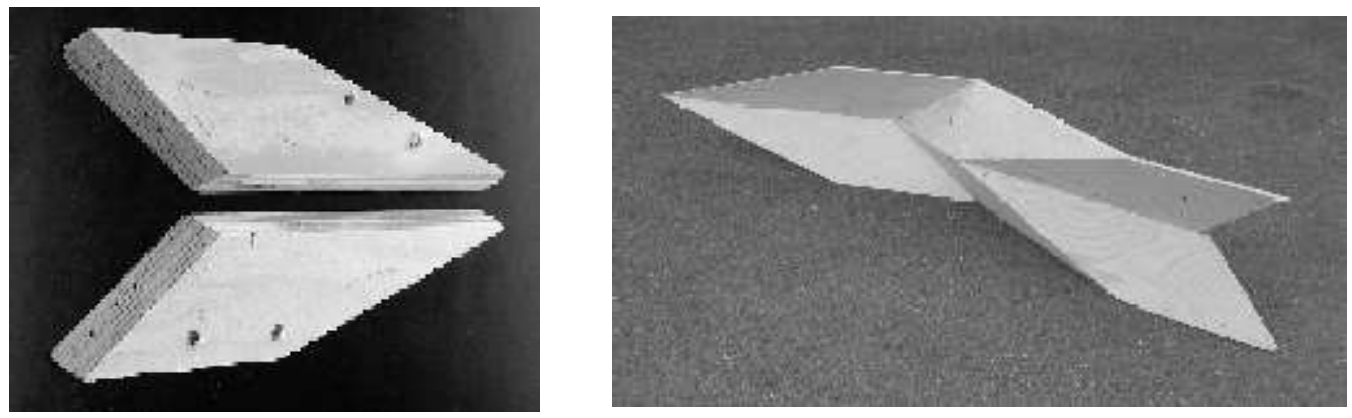

The prototype completed should pass the test showed important deformations of the structure particularly on the open sides. The results showed the importance of the connections in the proposed structures. The goal of the test is to improve the connections and to enhance the understanding of the general stiffness of the structure in relationship to the stiffness of the connections.
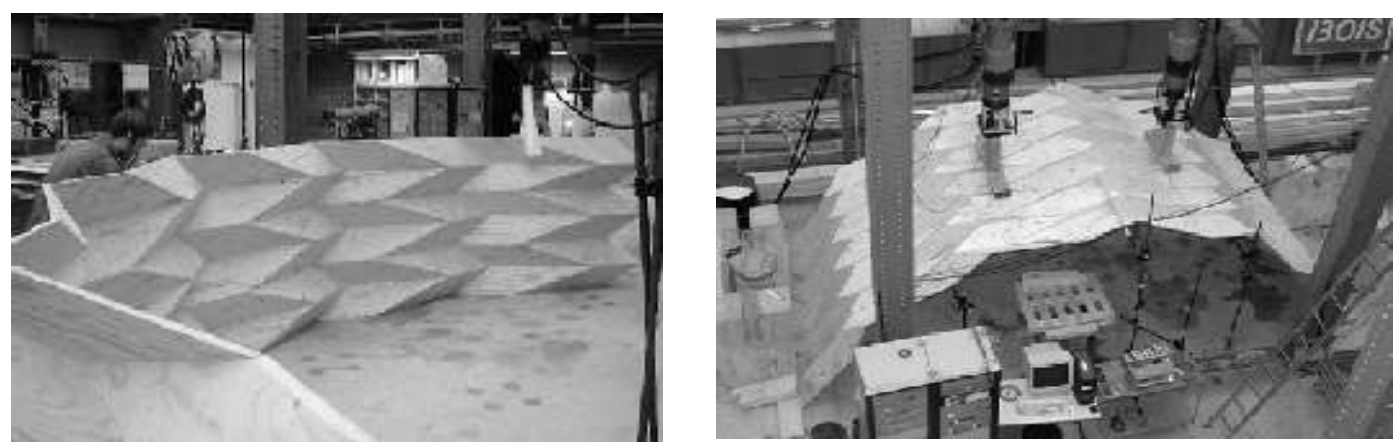
As an practical example, we can provide the practical design of a small chapel [11].The building is planned for about hundred persons. The architects wanted the chapel to remember the form of a basilica with one rounded nave. Two symmetrical, slightly bent, zigzag lines, define the form in plan. The basic corrugation is irregular such as the light reflection in the final shape is different on every panel. The section profile is a simple trapezoid. Due to the curve form of the basic corrugation the roof is compressed and rises up to a tip that recalls a little belfry. Some simple manipulations gave birth to a somehow familiar but discrete and original form (annex 1).
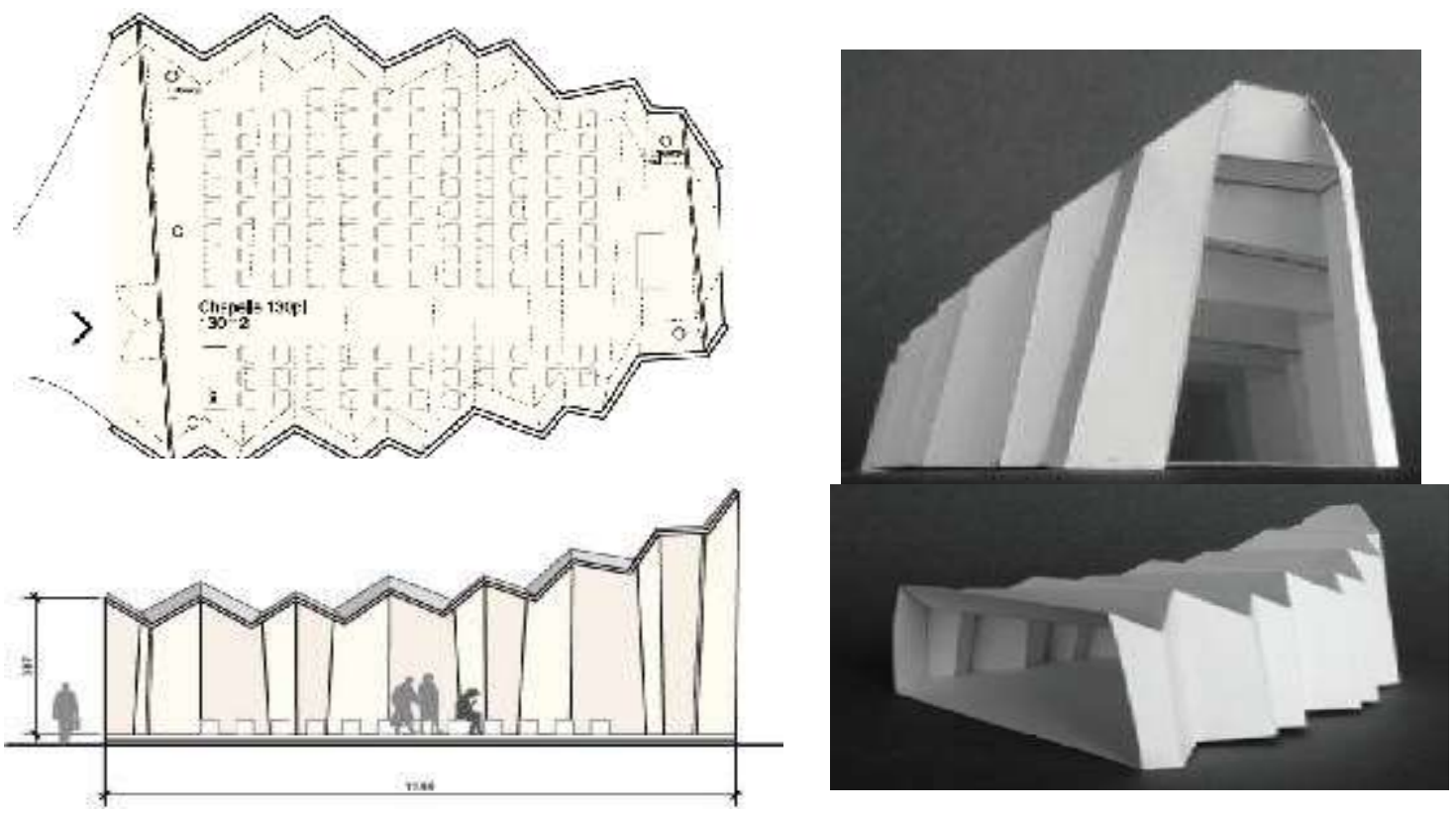

\section{The origami house and impact on the furniture design}

5.1. Origami can be applied not only in the decorations and furniture; it can be an inspiration for the base of the living house. The architects trying to use the origami mathematical parameters; however, there are other that are inspired the house on the figure 31, 32 located in Singarope. The Interior design of the house has been according to the origami parameters and shapes [2].
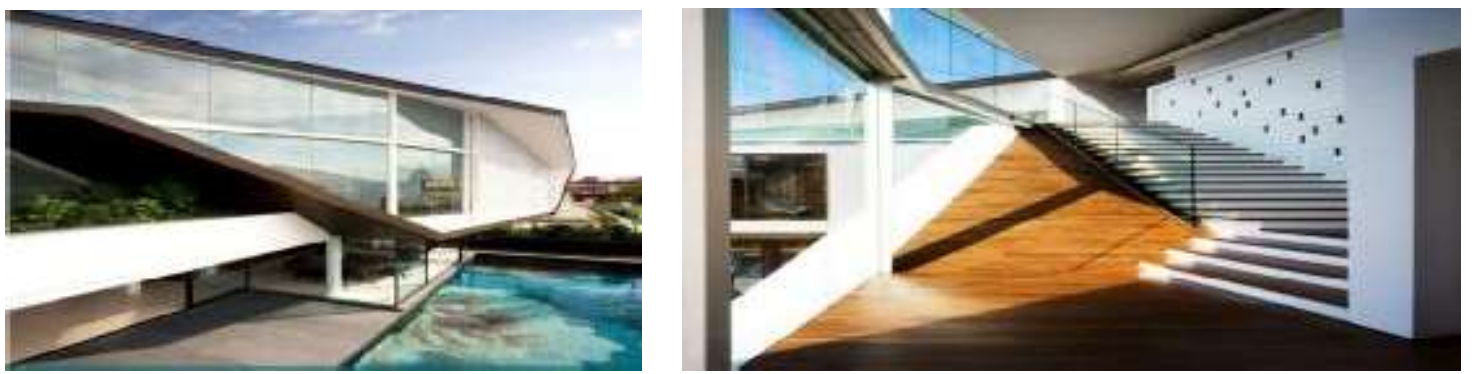
Adapting the concept of Origami - the geometric folding of a piece of paper to different shapes and forms- we attempt to depict the parent-child relationship in the way their dwelling spaces are intricately juxtaposed within the sculpted volumes created by the folding of bronze metal planes. While the child is being given her own private space, the parents still want to beable to watch over her from time to time and remain a big part of her life. Hence, the junior master suite has a strong visual dialogue with the master suite in the lower living and the upper study while the other remaining areas enjoy full privacy from the parents' supervision. The bronze metal 'sheet' forms both the roof scape of the house as well as the base of the bedroom volumes.

The sculptural volumes resulting from the Origami-like folds of the roof planes are complemented by several other sculptural elements or planes within the house like the suspended timber staircase cum vanity to basement powder room, the staircase to the basement, the suspended light shaft and the shading trellis over the living room void.
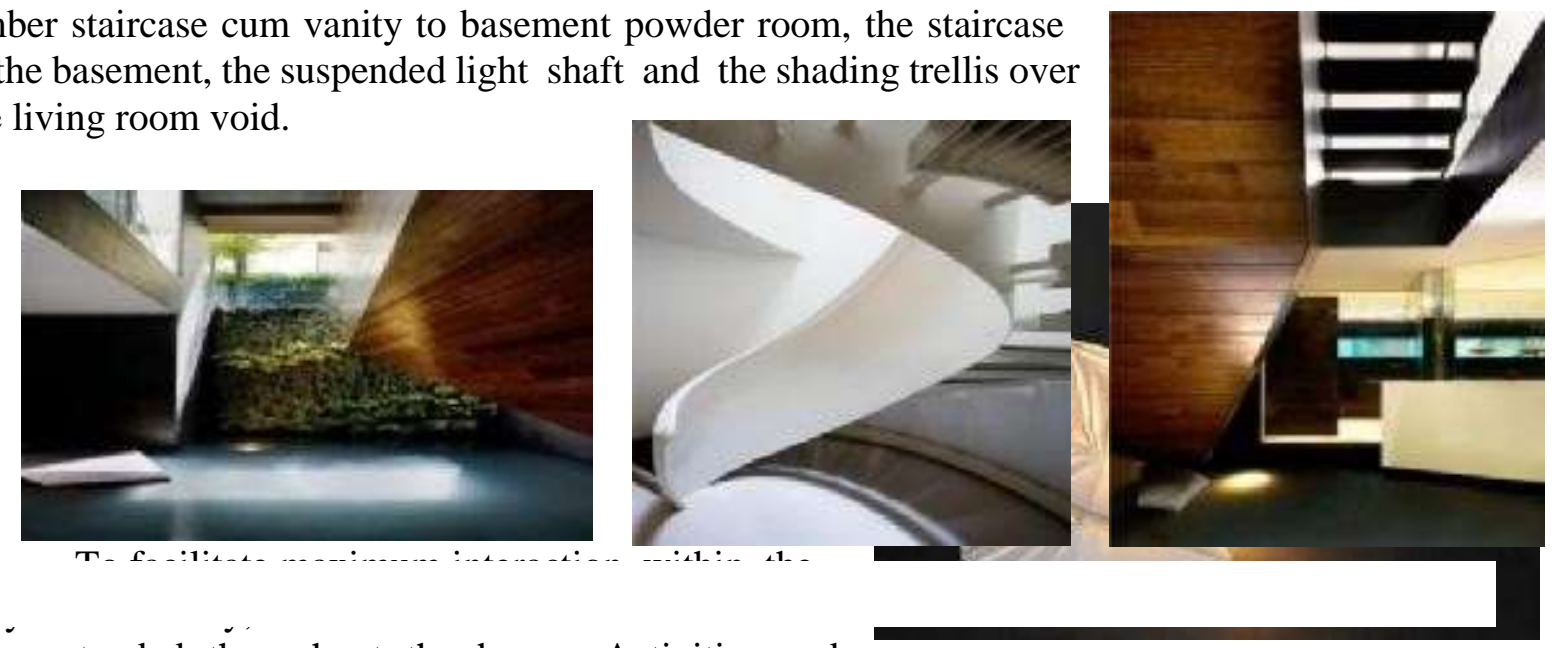

ve.

also extended throughout the house. Activities and movement within the house are being "shared"through the various connecting voids, bridges, picture windows and reflections off the reflective black glass surface. Even the swimming pool that takes on the role of a garden mural of bold floral prints is visually connected to the basement and hence lends a pictorial backdrop to the various rooms in the basement (the detail structure of the house presented in the Annex 2).

5.2. In general, the modern house in the origami style impress by the creativity, sophisticated design, by elegant shapes and lines. In addition, we would like to analyze the impact of the origami on the furniture and decorations. Furniture designers have been inspired by the simple elegance of this ancient form of art. Origami presents the furniture designer with endless possibilities; it allows furniture design to truly go beyond the "inside of the box". Everything from sofas and dining tables to lamps and curtains can be influenced by origami. The true beauty of origami lies in its innate ability to combine both function and beauty.

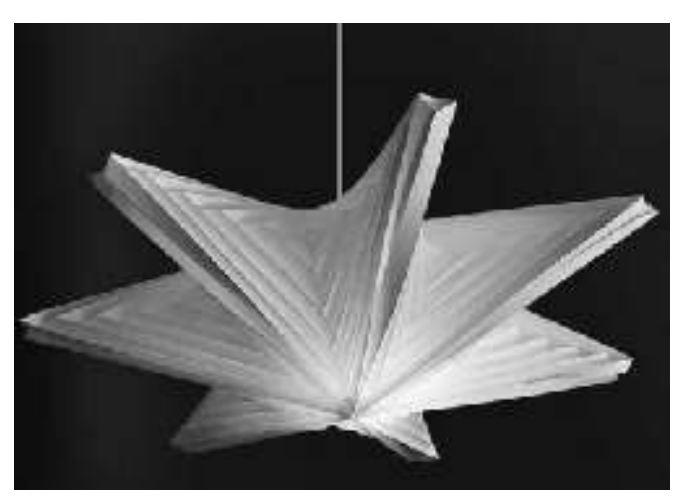


The origami is valuable in lighting design at the moment and it is translates into much larger scale in architecture.

The figures 36, 37 present unique lighting fixtures are made of $100 \%$ recycled paper and feature LED lights that save energy while creating contemporary lighting design [2]. Inspired by origami art, these lighting fixtures look original and innovative, offering beautiful lights for sensual interior decorating. The contemporary lighting fixtures are made of pieces of digitally-cut and hand-folded high quality cotton paper, and illuminated by custom-made LED lights. The lighting design provides a soft and bright light that highlights the intricacy and complexity of origami like pieces.

The lighting fixtures and beautiful and

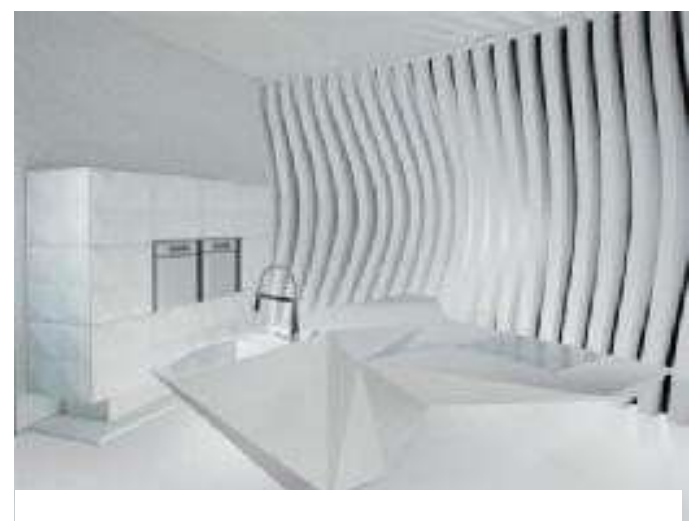
functional, blending aesthetic and practical into interesting lighting design. The contemporary lighting fixtures look like art, bringing new technology into modern interior decorating andenriching spaces with unique designer lights.

On the figure 38, we are showing the Karim Rashid design of a new unusual kitchen island concept inspired by the oriental art of folding paper. The shape is sculptural and looks like it's just there for display. But since it is made entirely of DuPont Corian, it is functional as well. It manufactured by the Egyptianproducer Amr Helmy.

Its base can expand into a large worktop, which is divided into three zones:

the cleaning area with an integrated sink, the cooking zone, and a snack area. Moreover, the island comes with a large wall cabinet with plenty of storage space.

Origami characterized by an apparently chaotic form, with sharp creases and folds, the origami-inspired style would ideally complement any modern minimalist interior design. The clean and simple yet visually interesting shapes give to ordinary products an artistic appeal that made designers to think out of the box and create ingenuous and original objects with sleek, distinctive and light weight design. The materials bend and fold to form modern, elegant and surprisingly comfortable decor elements for interiors whose vibration resides in an extremely dynamic atmosphere.

The figure 41 , inspired by paper craft, the idea behind the chair shows that folding simple shapes can then create cool, sculptural forms. The nest-like shape offers plenty of

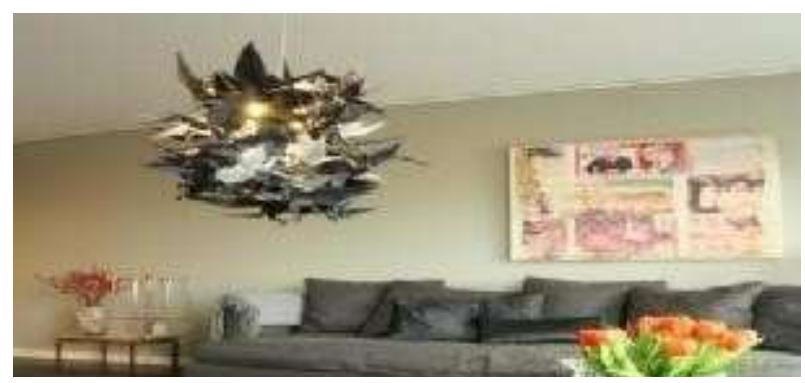


room and its ergonomic baltic birch shell is minimal and efficient.

The sections of the shell are connected with piano hinges giving it the facets. It also gives the chair some wiggle room. The shell of the chair is being made in different finishes, as well as solid-color laminates, and sits atop a folded steel frame.

As far as we see the origami presents the wide variety of the possibilities for the Designers nowadays. All what is needed is not to hold the own creativity and not to be afraid to go beyond the limits. 


\section{CONCLUSION:}

\section{"In the beginning we didn't know what would be possible, but then we tried to push the limits and eventually found that everything could be made. "}

ERIK DEMAINE

Architecture has traditionally been known as the art that covers the three major artistic disciplines:

1. In the current contemporary context of creation and thanks to the influence of the new artistic languages and means of creation, the architectural project may be ephemeral, ethereal and audiovisual, a temporary urban installation, and no longer exclusively eternal heavy and immobile. Cross disciplinarily of artistic genres that today represent diversified cultural production offers new opportunities for action and reflection, research and creation

2. In an intuitive approach, hands-on experience by paper folding allowed identifying three patterns particularly interesting for construction with cross laminated timber panels.

3. Geometrical analysis showed that the folded patterns can be generated by two polygonal lines. This allows representing rapidly complex folded plate structures in space as well as unfolded. A great variety of forms can be generated. For the moment the type of form is limited to simple curved surfaces. In paper folding some patterns can easily be deformed to double curved surfaces with radial or spherical form. Further investigations will show if it is possible to extend the method to such forms.

Traditional art of Origami which has served and still serves as creative inspiration enhances its maximum expressiveness as a medium and as a catalyst for research. As a field of interference between innovations in artistic media, spatial geometries and building materials that enable multiple and heterogeneous applications of architecture, it offers to us a global vision andat the same time a focal point, a thread of narrative intensity and creative potential 


\section{REFERENCES:}

1. Bechthold, M, 2007. Surface Structures in the Digital Age: Studies in Fibrocement. In LloydThomas, K. ed. 2007. Material Matters: Architecture and Material Practice. London: Routledge, pp: 139-150

2. Brown P. (2013). Origami love. - Design and Paper

3. Cassinello, F. (1961). Estructuras Plegadas. Informes de la Construcción. Madrid

4. Demaine, E. and O'Rourke, J.: 2007, Geometric Folding Algorithms: Linkages, Origami, Polyhedra; Cambridge University Press.

5. Demaine, E.; Demaine, M.; Hart, V.; Price, G. and Tachi, T.: 2011, (Non)existence of Pleated Folds: How Paper Folds Between Creases, in Graphs and Combinatorics, Volume 27, Is-sue 3, Springer Japan, 341-351

6. Fox. M and Yeh, B: 2000, Managing Interactions in Smart Environments, Springer, 91- 103.

7. Hunt G., Airo I., Twist buckling and the foldable cylinder: an exercise in origami, International Journal of Non-Linear Mechanics 40, 2005, pp 833-843

8. International Arts \& Artists (2008). The Infinite Possibilities of Origami - folding paper.

- Education Packet.

9. International art and artists (2013). New Expression in Origami - above the fold. Education Packet.

10. Iwamoto, L. (2009), Digital Fabrications, Architecture and Material techniques. Princeton Architectural Press

11. Lang, R.: 2010, Origami and Geometric Constructions.

12. Miura K., Folding a plane- scenes from nature technology and art, Symmetry of structure, interdisciplinary Symposium, , Aug 13-19, Danvas G. \&Nagy D. ed., Budapest, Hungary, 1989, pp 391-394

13. Nerdinger, et al (2002), Bruno Taut 1880-1938. Milano, Electa

14. Origami House Architecs (2012). - HomeDesign

15. www.pinterest.com

16. commons.wikimedia.org

17. colourfulhome.wordpress.com

121. Maha Elsayed Mohamed Ramadan, and Maha Mohamed Imam Elhalabi, Integrative iRelationship Between Environmental Architecture and Interior Design Towards 'Sustainability, International Journal of Multidisciplinary Studies in Art and Technology, Vol (1), Issue (2), 2018, 4-6.

122. Maha Mahmoud Ibrahim, Beyond Sustainability -Towards Restorative Interior Spaces ithrough Biophilic Design, International Journal of Multidisciplinary Studies in Art and

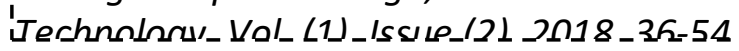




\section{ANNEX 1}

The final Design of the Chapel:

Built directly on the ground, the new chapel blends subtly and delicately with the landscape. Interpreting the traditional layout of protestant churches, the design creates a space who's horizontal and vertical dimensions vary via a series of origami-like folds, which give rhythm to the interior and exterior of the building

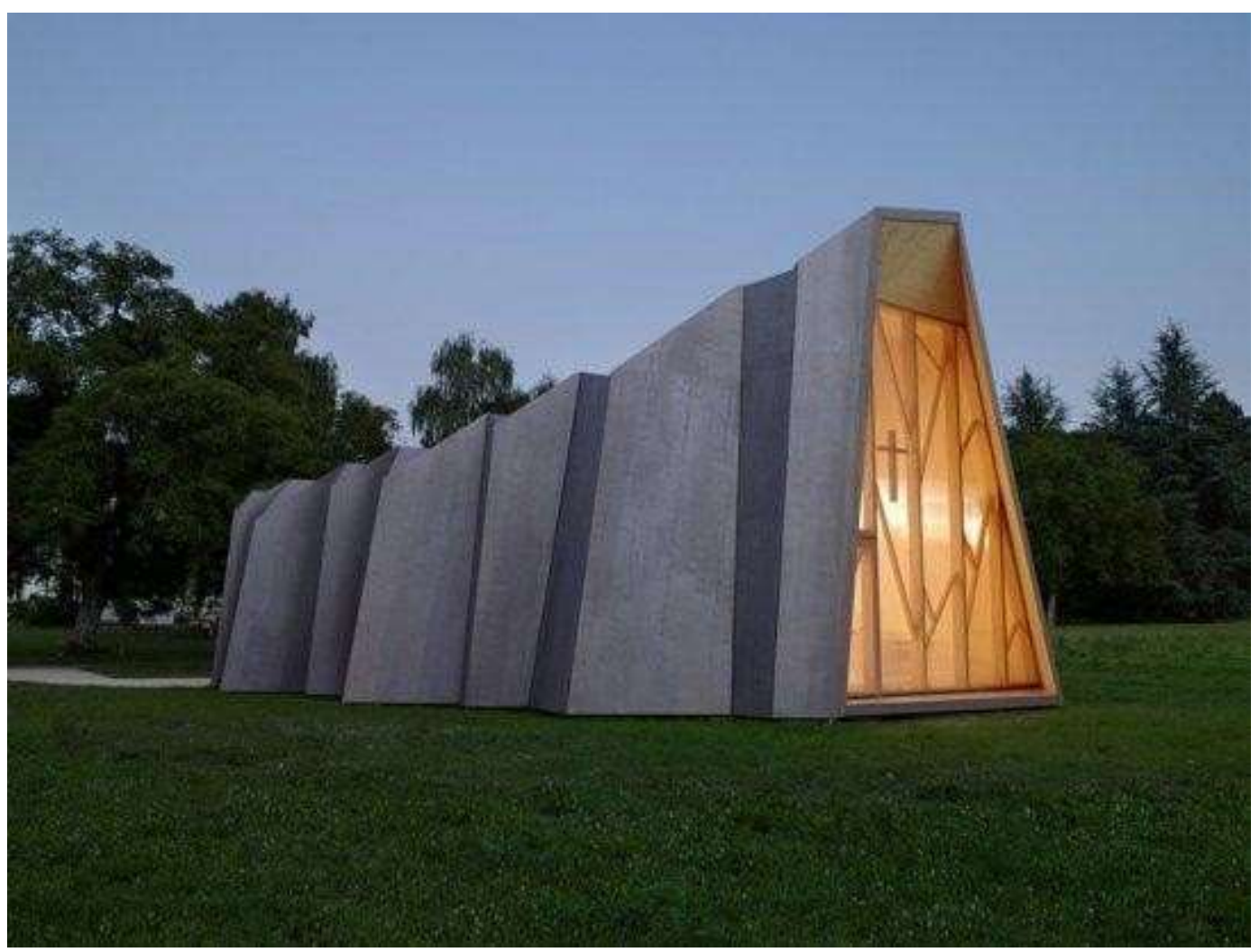

Source: [] 


\section{ANNEX 2:}

The plan of the origami house
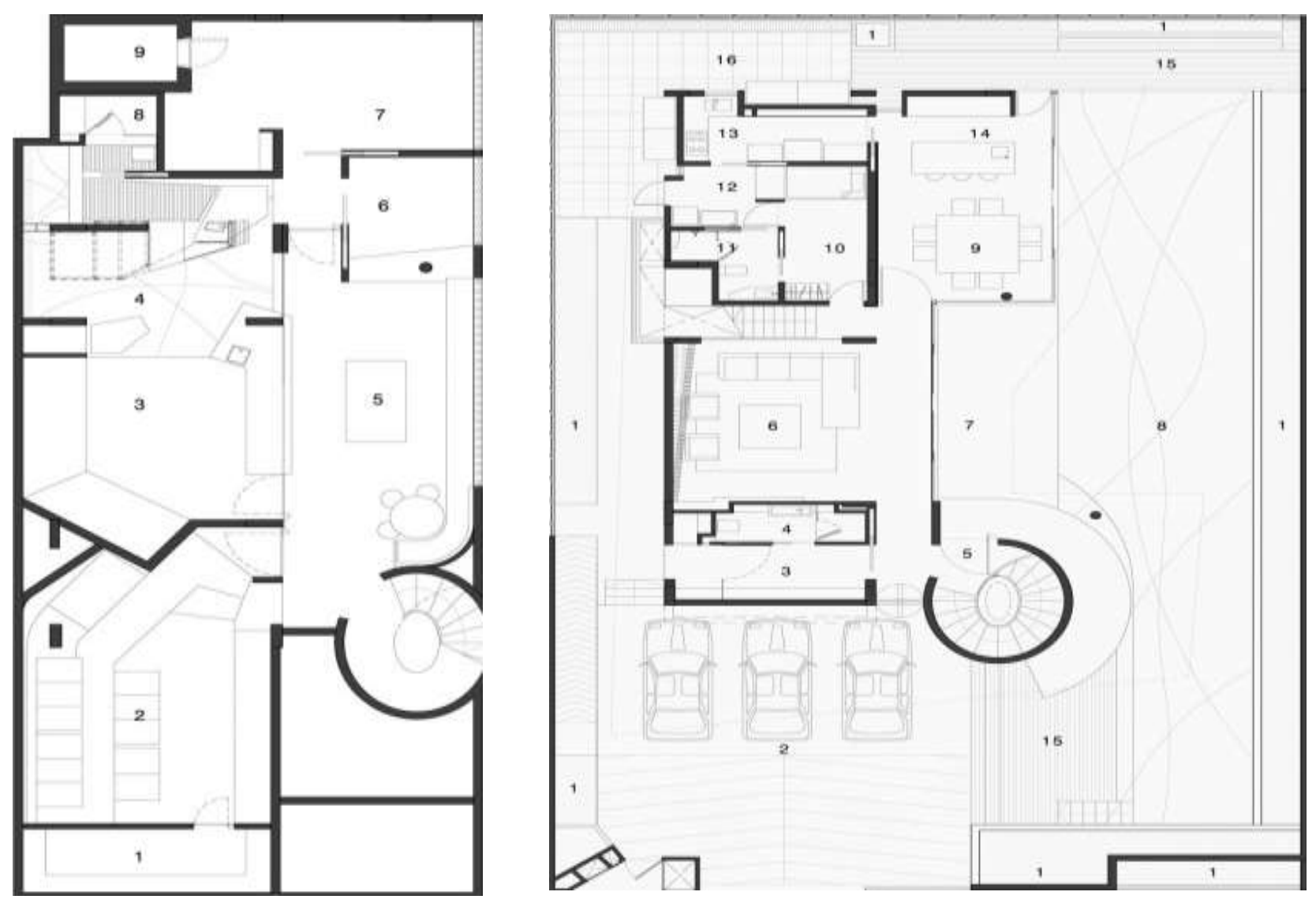


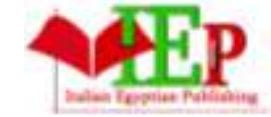

ISSN: 2735-5365
INTERNATIONAL JOURNAL OF

DESIGN AND FASHION STUDIES
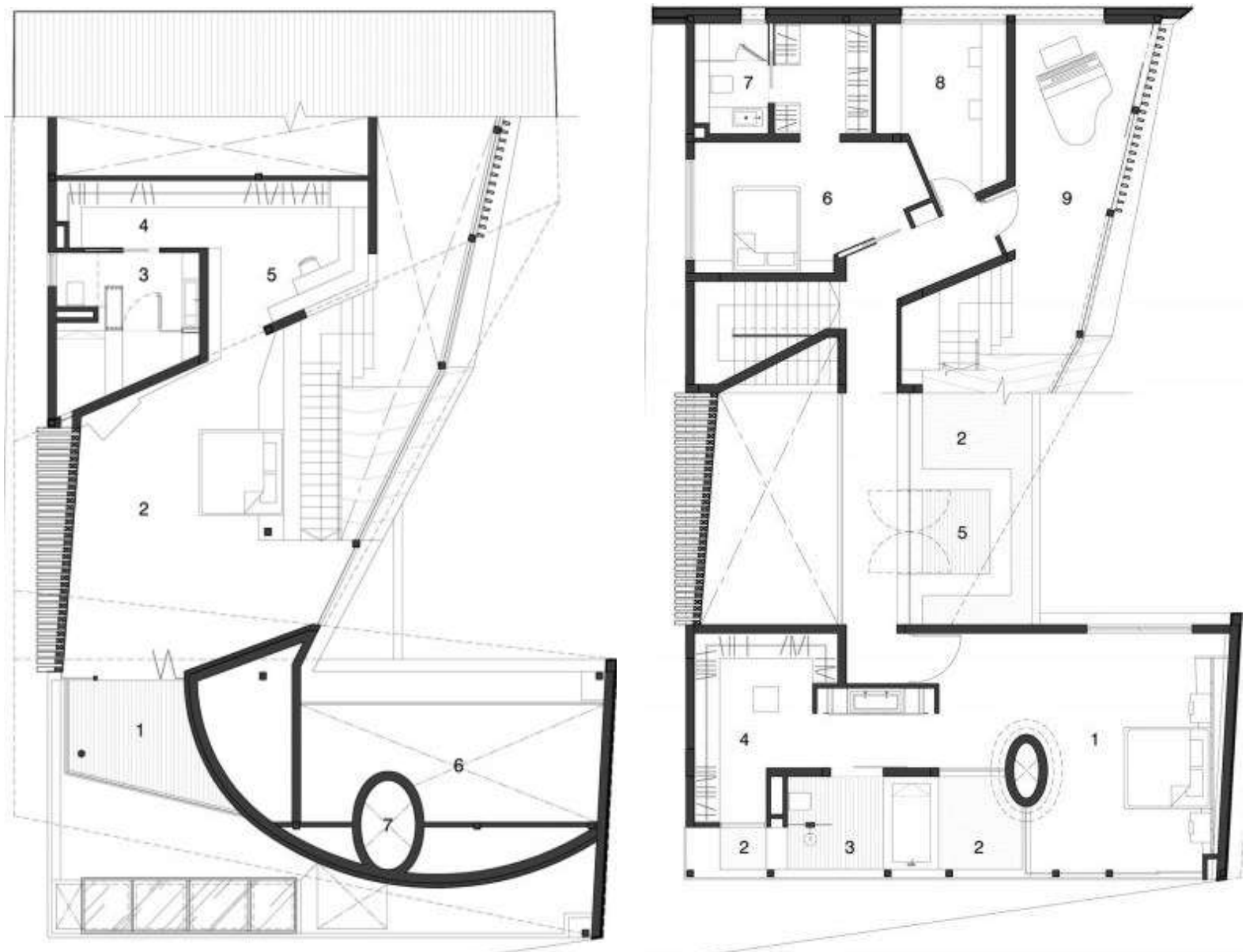



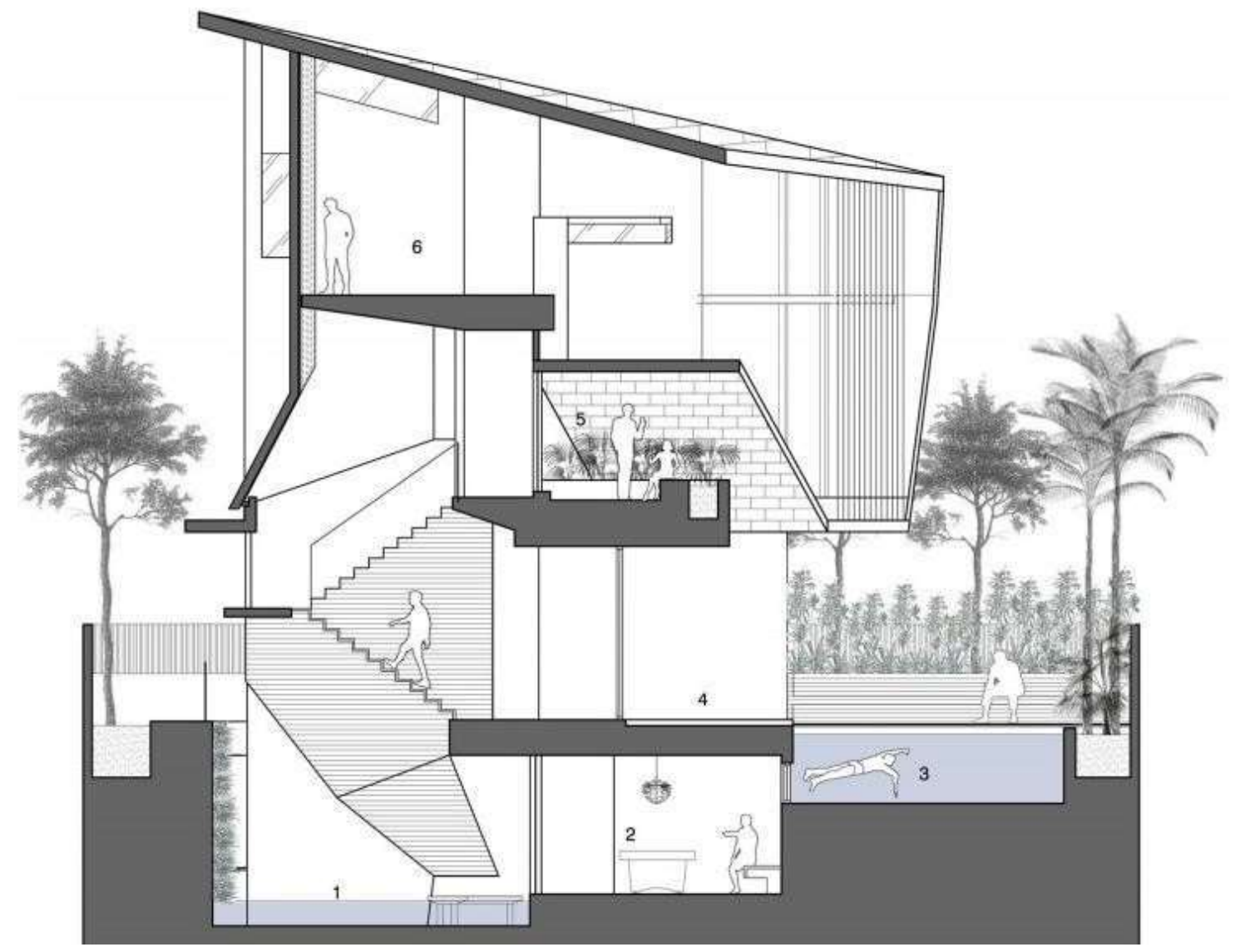

1. Reflective Pool

2. Lounge Area

3. Swimming Pool

4. Outdoor Deck

5. Junior Master Suite

Received: April 2020

Accepted: June 2020 